\title{
Applying an Extended Kernel Density 4-Step Floating Catchment Area Method to Identify Priority Districts to Promote New Publicly Financed Supply of Gastroenterology Exams
}

\author{
Pierre Polzin ${ }^{1}$, José Borges $^{2} \&$ António Coelho ${ }^{2}$ \\ ${ }^{1}$ Faculty of Engineering, University of Porto, Portugal \\ 2 INESC TEC Technology and Science, Faculty of Engineering, University of Porto, Portugal \\ Correspondence: Pierre Polzin, R. Dr. Roberto Frias, 4200-464 Porto, Portugal. E-mail: ppolzin@ers.pt
}

Received: December 19, 2016 Accepted: January 4, 2017 Online Published: January 25, 2017

doi:10.5539/jms.v7n1p1 URL: http://dx.doi.org/10.5539/jms.v7n1p1

\begin{abstract}
In continental Portugal, the publicly financed supply of gastroenterology exams was limited since the end of the last century, restricted to a fixed set of private providers that was hired by the Portuguese state. This way of contracting created market entry barriers and is inefficient, since prices are administratively set. Besides, it produced access inequalities, because of the way that the supply was geographically distributed. This paper applies the Extended Kernel Density 4-Step Floating Catchment Area (EKD4SFCA) method to identify priority districts for the promotion of new supply by the state, in order to choose the appropriate way of contracting new private supply, as determined by current law, and to reduce access inequalities. The applied method enables the identification of the Portuguese regions with strong competition between health care providers and where patients' access to publicly financed gastroenterology exams is relatively low. In these regions, the state should promote public bids to stimulate new supply, exploring thereby the potential for setting lower prices and reducing access inequalities.
\end{abstract}

Keywords: spatial analysis, competition analysis, public financing of care provision low case

\section{Introduction}

The EKD4SFCA method provides a combined analysis of competition and access by incorporating the Herfindahl-Hirschman Index (HHI) and a market dominance identification technique in the Extended Kernel Density 2-Step Floating Catchment Area (EKD2SFCA) method (Polzin et al., 2014, 2016).

As far as competition analysis is concerned, an innovation of the EKD4SFCA method is the adaptation and extension of the HHI index and of the dominance identification method of Melnik et al. (2008) for their application with small geographic units of analysis, a distance decay function and catchment areas. This way, fine-resolution results are obtained, which provide detailed information that can be useful for public policies in Portugal to manage financing of private health care provision in accordance with the legislation. Actually, since 2013, after Decree-Law 139/2013 came into effect, public financing of diagnostic exams carried out by private health care providers in continental Portugal became dependent on a prior appraisal of the existing competitive situation in health care markets. In competitive geographic markets, public bids have to be promoted to explore competition and attain lower prices. In other regions, free adhesion contracts can be signed, which may facilitate entry of new providers into concentrated markets.

This paper presents an application of the EKD4SFCA method to identify priority districts for the promotion of new supply of gastroenterology exams by the state, in order to choose the appropriate way of contracting private supply, as determined by law, and to reduce existing access inequalities.

It has been acknowledged that the populations have been facing problems in obtaining colonoscopies in Portugal that lead to insufficient diagnosis and treatment of gastrointestinal diseases. If new supply capacity is not promoted, a heightening of the number of deaths due to malignant neoplasms of colon, rectum and anus should be expected, as the illustrated forecasts from 2014 until 2025 indicate in Figure 1. (Note 1) 


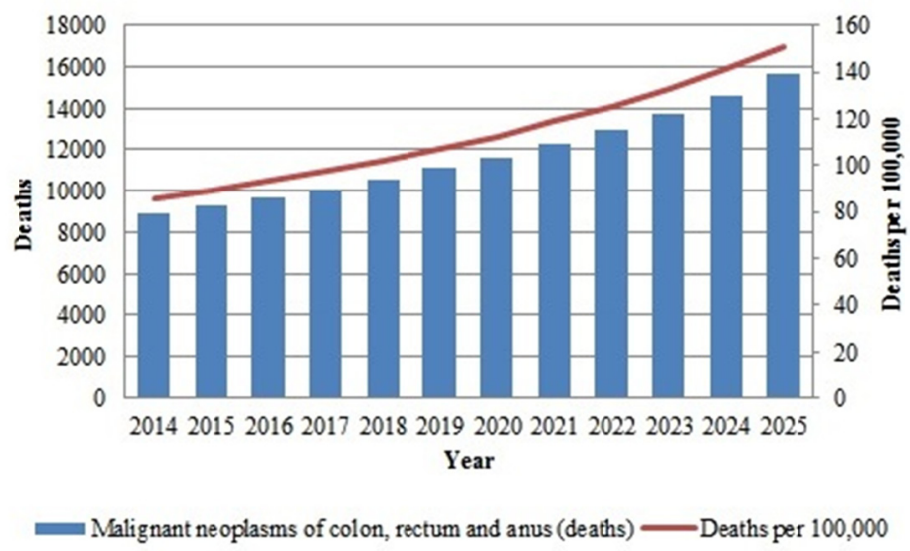

Figure 1. Deaths in Portugal due to malignant neoplasms of colon, rectum and anus

\section{Methods}

The EKD4SFCA method is constituted by the extended HHI and an extended dominance identification technique, which are adopted for competition analysis, and the EKD2SFCA method, which is dedicated to patients' access analysis.

Competition analysis can be defined as the assessment of firms that are selling products or services in a market, and the examination of their different performances and relative positions in the market. In this paper we follow the structure/conduct/performance framework, such that we assume that more concentrated markets reflect less competition, while low concentration indicates that there is strong competition in the market (CC, 2013; Halbersma et al., 2011; Hellmer \& Wårell, 2009). Thus, we rely our analysis on the adoption of market concentration assessment metrics that depend on the number of firms that are active in the market and their respective market shares.

This information can also indicate whether the market is dominated by incumbent firms with substantial market power. Market dominance is a condition that, if verified, may generate an impediment to competition.

Regarding access to health care, it is regarded in this paper as potential access, which is defined as the presence of enabling resources. These are resources that are required for utilization to take place (Andersen, 1995; Graves, 2009; Gulzar, 1999; Higgs, 2004). The analysis that considers enabling resources can identify disadvantaged populations, that is, populations that face potential access barriers.

\subsection{Competition Assessment Methods}

The HHI was developed by Hirschman and Herfindahl in their 1945 and 1950 works, and it is calculated as the sum of the squares of the firms' market shares in the market that is being analyzed by the researcher (Hirschman, 1964; Rhoades, 1993). It enables the calculation of degrees of market concentration giving an indication of the competitive pressure between firms that are active in a market, and it reflects the market share inequality across the spectrum of firms that compete in a market.

Its application for industries in which consumers travel to supply points to obtain the needed products presents four limitations, however:

1) Disregard of border crossing of consumers: market concentration is assessed in each chosen geographic market considering only the supply points located in that region;

2) There is no variability in market concentration within the regions that are defined as the relevant geographic markets;

3) The HHI treats large distances inside the geographic markets the same way as small distances;

4) Any modification of the regions chosen to assess competition may produce variations on the result for a specific enclosed small geographic area.

The extended HHI alleviates these limitations by using catchment areas as geographic markets, small geographic units of analysis, and a distance decay function: 


$$
H H I_{i}^{E}=\sum_{G=1}^{N}\left[\sum_{l \in\left\{d_{i l} \leq d_{\max }\right\}} \mathrm{Q}_{G l} g\left(d_{i l}, d_{\max }\right)\right]^{2}
$$

where $H H I_{i}^{E}$ is the extended HHI calculated for the geographic unit $i$, and $G$ refers to groups of supply points, namely the firms or economic groups that own the supply points $(G=1$ is the largest group, $G=2$ is the second largest group, and so on, until the smallest group competing in the market $i$, namely $G=N$ ). The expression inside the square brackets in equation (1) refers to the market share of group $G$ with supply points located at $l$ that have catchments covering $i$, and $g\left(d_{i l}, d_{\max }\right)$ is a distance decay function, while $d_{\max }$ is the travel time that defines the boundaries of the catchment areas.

This way of calculating the HHI makes it possible to identify in a detailed way the competitive pressure between firms in each of the small geographic areas of a study region, taking into account the potential flows of the populations from their residences to the supply points.

While the HHI is applied at the industry level, the dominance identification method of Melnik et al. (2008) is applied at the firm level. It is a competition assessment method that enables the identification of market dominance by considering how existing competition limits the ability of a firm to dominate the market. It considers the market shares of all competing firms in an industry to calculate a dominance threshold. If the firm with the largest market share has a greater share than the dominance threshold, then it has a dominant position (Hellmer \& Wårell, 2009; Melnik et al., 2008).

As proposed by Knoche \& Thöni (2011) and McIntosh \& Hellmer (2012), this method complements any competition assessment that is initiated with the HHI. However, it presents the same four problems of the original HHI, namely problems (i) to (iv) identified above. In order to alleviate these problems, the extended version of the method uses catchment areas, small geographic assessment units and a distance decay function, as it is described by equation (2):

$$
\mathrm{Q}_{i}^{D^{E}}=\frac{1}{2}\left\{1-\left[\left[\sum_{l \in\left\{d_{i l} \leq d_{\max }\right\}} \mathrm{Q}_{1 l} g\left(d_{i l}, d_{\max }\right)\right]^{2}-\left[\sum_{l \in\left\{d_{i l} \leq d_{\max }\right\}} \mathrm{Q}_{2 l} g\left(d_{i l}, d_{\max }\right)\right]^{2}\right]\right\}
$$

which is the extended calculation of the dominance threshold for the geographic unit $i$. The variables, the distance decay function and $d_{\max }$ are the same ones as in equation (1), of the extended HHI.

\subsection{Access Assessment Method}

As remarked before, we adopt the EKD2SFCA method to analyze access. This method uses floating catchment areas and computes access scores for small geographic units (Polzin et al., 2014). In 2SFCA-based methods like the EKD2SFCA, the catchment areas are floating areas, because the computation of the scores depends on catchment areas centered on the centroids of each of the small geographic units of the study region. All scores are thus computed by a window that is moved across the study region (Luo \& Wang, 2003; Yang et al., 2006). This is also the logic behind the extended versions of the HHI and the dominance identification method presented in the previous section. The floating catchment areas make it possible to compute HHI degrees and dominance thresholds for all small geographic units of a study region.

Equation (3) summarizes the two steps of the EKD2SFCA:

$$
A_{i}^{E}=\sum_{l \in\left\{d_{i l} \leq d_{\max }\right\}} \frac{S_{l}}{\sum_{k \in\left\{d_{k l} \leq d_{\max }\right\}} P_{k} H_{k} g\left(d_{k l}, d_{\max }\right)} C_{i} g\left(d_{i l}, d_{\max }\right)
$$

Where $A_{i}^{E}$ is the computed overall access score of the population that resides in the geographic unit $i, S_{l}$ is the supply capacity of the supply point georeferenced at $l$, measured as the number of physicians or beds, for instance, $P_{k}$ is the population of the geographic unit georeferenced at $k, H_{k}$ is the health needs score of the population at $k, d_{k l}$ is the travel time between $k$ and $l$, and $d_{\max }$ is the maximum travel time that defines the size of the catchment areas. Finally, the distance decay function is represented by $g\left(d_{k l}, d_{\max }\right)$ and $g\left(d_{i l}, d_{\max }\right)$, and $C_{i}$ refers to the commuting score of the population at $i$ computed with representative variables of the mobility of the populations when accessing health care.

The distance decay function used in equations (1), (2) and (3) is the quartic function, which is applied only after an initial catchment $d_{\text {init }}$ until $d_{\text {max }}$ : 


$$
g\left(d_{i j}, d_{\max }\right)=\left\{\begin{array}{lll}
1 & \text { if } & 0<d_{i j}<d_{i n i t} \\
\frac{15}{16}\left[1-\left(\frac{d_{i j}}{d_{\max }}\right)^{2}\right]^{2}, & \text { if } & d_{i n i t} \leq d_{i j} \leq d_{\max } \\
0 & \text {,if } & d_{i j}>d_{\max }
\end{array}\right.
$$

The initial catchment $d_{\text {init }}$ is used as proposed by McGrail \& Humphreys $(2009,2009,2009)$, Schuurman et al. (2010) and Polzin et al. (2014, 2016), assuming that travel times below a predetermined threshold do not present any sensible proximity impediment to utilization.

\section{Results}

The competition analysis presented in the next section is based on an application of the extended versions of the $\mathrm{HHI}$ and the dominance identification technique. Table 1 presents the distribution of private facilities or supply points that provide gastroenterology exams across the 18 districts and in the whole continent of Portugal, namely the numbers with contract for publicly financed provision and total (with and without contract). (Note 2) It also shows the number of firms that own supply points in each of the districts and continent. The total number of firms of continental Portugal is not equal to the sum of the firms with supply points in the districts, because there are firms competing in more than one district. We also note that of the 502 firms competing in the continent, only 147 of them have contract for the provision of publicly financed gastroenterology exams.

Table 1. Number of private supply points and firms

\begin{tabular}{|c|c|c|c|}
\hline \multirow{2}{*}{ District } & \multicolumn{2}{|c|}{ Number of supply points } & \multirow{2}{*}{ Number of firms } \\
\hline & With contract & Total & \\
\hline Aveiro & 31 & 57 & 47 \\
\hline Beja & 0 & 4 & 4 \\
\hline Braga & 29 & 47 & 38 \\
\hline Bragança & 2 & 9 & 8 \\
\hline Castelo Branco & 3 & 13 & 13 \\
\hline Coimbra & 25 & 64 & 49 \\
\hline Évora & 0 & 10 & 10 \\
\hline Faro & 0 & 25 & 18 \\
\hline Guarda & 1 & 7 & 6 \\
\hline Leiria & 20 & 42 & 32 \\
\hline Lisboa & 20 & 158 & 126 \\
\hline Portalegre & 0 & 6 & 5 \\
\hline Porto & 48 & 105 & 80 \\
\hline Santarém & 15 & 39 & 33 \\
\hline Setúbal & 9 & 57 & 52 \\
\hline Viana do Castelo & 1 & 10 & 8 \\
\hline Vila Real & 4 & 13 & 11 \\
\hline Viseu & 7 & 26 & 24 \\
\hline Continental Portugal & 215 & 692 & 502 \\
\hline
\end{tabular}

The distribution of supply points across the districts in quartiles is illustrated in Figure 2. 


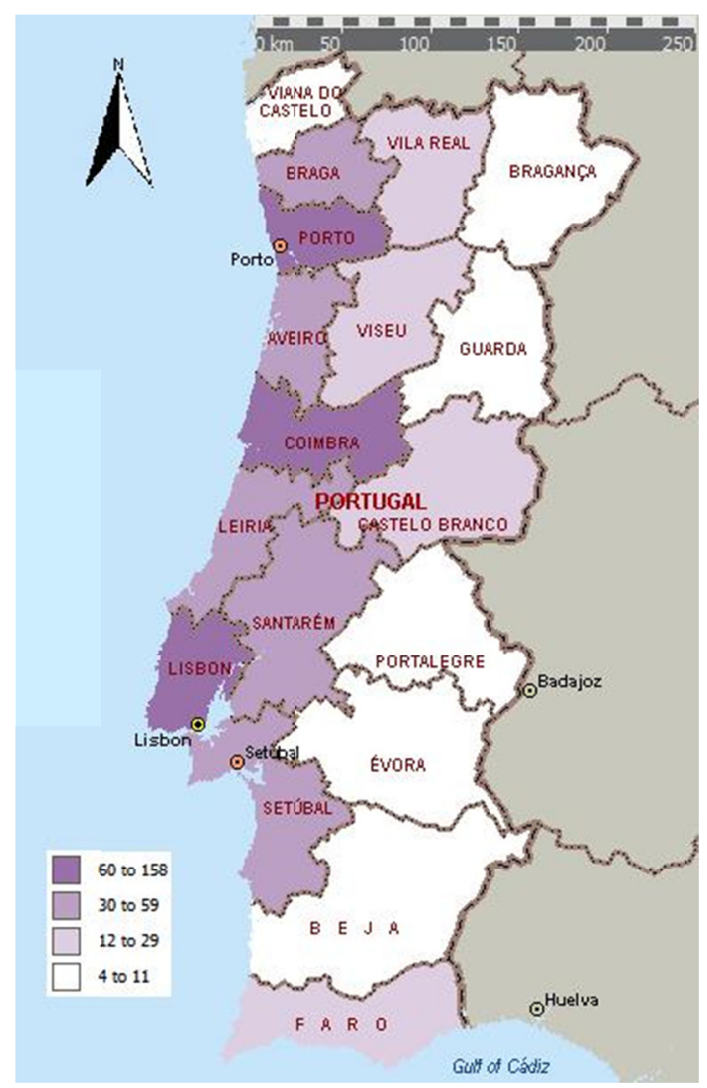

Figure 2. Geographic distribution of the supply points

\subsection{Competition Analysis}

The extended versions of the HHI and the dominance identification technique identified in equations (1) and (2) are applied in a similar way as proposed by McIntosh \& Hellmer (2012). Thus, if the HHI is over 2,000 and the geographic units are dominated, the identified geographic markets will have the highest risk of presenting competition problems, such that only in other regions it will be possible to explore competition with public bids.

Table 2 presents the results identifying the numbers of postcode areas with and without potential competition problems per district. We also indicate the number of residents of the postcode areas in each of the identified regions. (Note 3)

Table 2. Competition assessment results for postcode areas and districts

\begin{tabular}{lllll}
\hline \multirow{2}{*}{ District } & \multicolumn{2}{c}{ With competition problems } & \multicolumn{2}{c}{ Without competition problems } \\
\cline { 2 - 5 } & N. of postcode areas & Population & N. of postcode areas & Population \\
\hline Aveiro & 7 & 197,627 & 18 & 516,591 \\
Beja & 6 & 68,535 & 0 & 0 \\
Braga & 6 & 166,581 & 19 & 661,146 \\
Bragança & 3 & 29,291 & 1 & 35,341 \\
Castelo Branco & 5 & 100,769 & 4 & 63,082 \\
Coimbra & 10 & 132,514 & 14 & 292,992 \\
Évora & 11 & 117,135 & 2 & 35,212 \\
Faro & 10 & 180,496 & 7 & 214,077 \\
Guarda & 6 & 93,781 & 1 & 770 \\
Leiria & 11 & 145,246 & 16 & 325,649 \\
Lisboa & 7 & 200,519 & 61 & $2,035,635$ \\
Portalegre & 5 & 43,347 & 6 & 52,892 \\
Porto & 7 & 157,556 & 46 & $1,658,617$ \\
Santarém & 7 & 113,557 & 18 & 296,338 \\
Setúbal & 10 & 182,594 & 20 & 662,981 \\
Viana do Castelo & 7 & 137,839 & 2 & 39,023 \\
Vila Real & 4 & 70,733 & 5 & 84,552 \\
Viseu & 12 & 134,482 & 13 & 199,873 \\
\hline & & 5 & &
\end{tabular}


We note that the Geographic Information System (GIS) used for the application of equations (1) and (2) was Microsoft MapPoint 2013. This GIS supplied the average speed maps, the traffic rules, the subdivisions of the study region, and the centroids of 459 four-digit postcode areas of continental Portugal, which are required to compute the travel times and to define the sizes of the catchment areas.

The catchment areas sizes are defined by the maximum travel times that consumers are willing to travel to reach the products and services that they need or desire. The orientation by the Portuguese Health Regulation Agency for the maximum travel time to diagnostic exams in Portugal is 30 minutes, which is the reference for the floating catchment areas that we use in this study.

Market shares were calculated with information on the supply capacity, more specifically the number of physicians. According to the European Commission, in its Notice on the definition of relevant markets, the capacity constitutes a valid parameter to be used in the calculation of market shares (EC, 1997).

Finally, we also note that we used an initial catchment $d_{\text {init }}$ of 10 minutes for the calculations of the extended HHI degrees and dominance identification market shares, as proposed by Polzin et al. $(2014,2016)$. However, small changes to this travel time reference will not produce significant variations to the results. As we could confirm in this study after applying the Friedman rank sum test and the post hoc test with Bonferroni correction, no significant differences occur if $d_{\text {init }}$ is changed to 5 minutes or to 15 minutes. (Note 4 )

Figure 3 shows the results for the districts. For this aggregation, we considered the association of the results with the populations, such that the result shown for each district is the one that is spread over the highest number of residents.

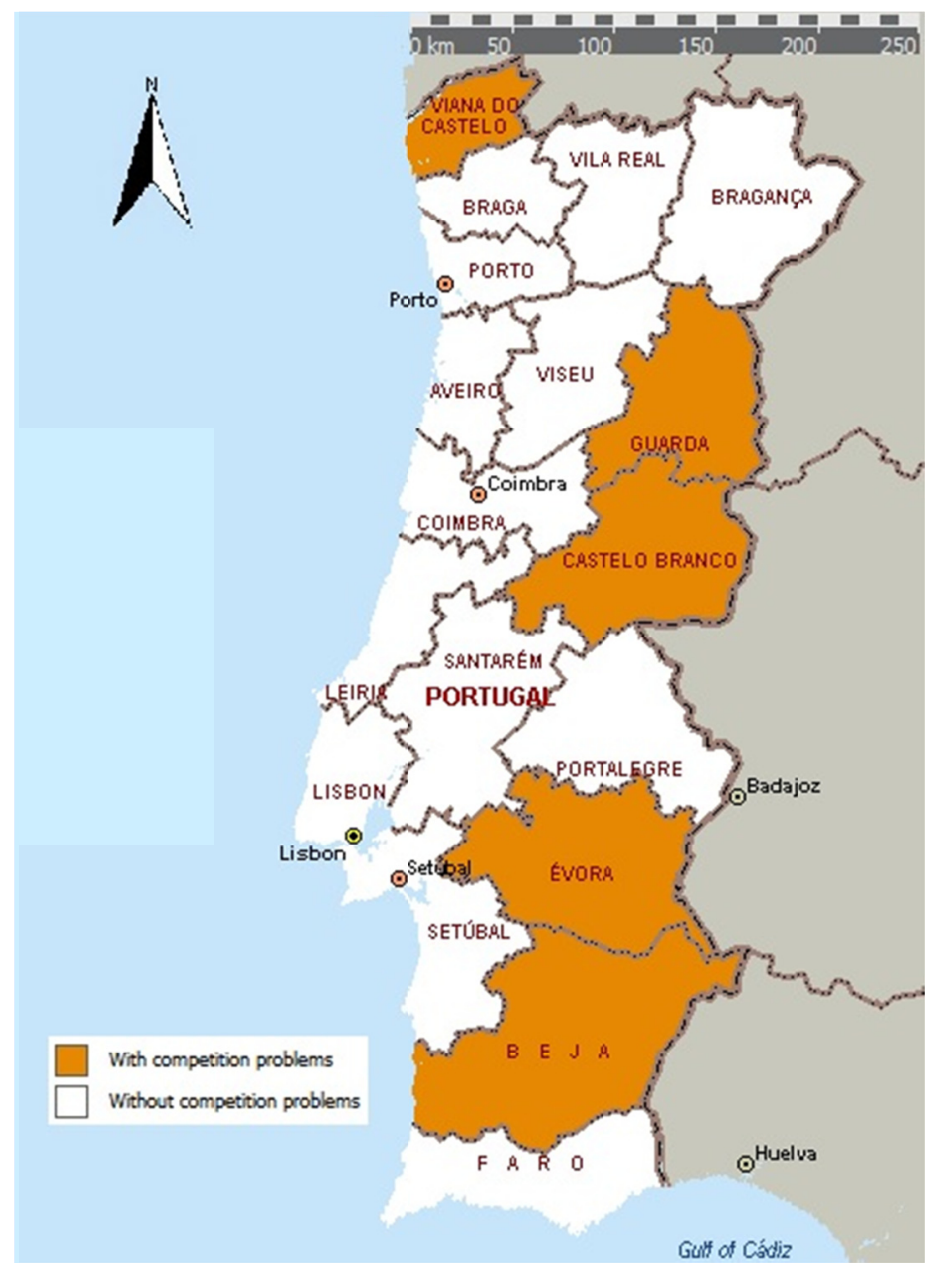

Figure 3. Competition results

As it is illustrated in the figure, the regions with predominantly weak or lack of competition are the districts of Beja, Castelo Branco, Évora, Guarda and Viana do Castelo. In these districts public bids should be avoided and 
free adhesion contracts directed to new providers would be best to promote competition. In the other districts, the state could promote public bids to better manage public financing, aiming to explore competition and attain lower prices.

\subsection{Access Analysis}

Now, after obtaining the competition assessment results, it is possible to apply the full EKD4SFCA method and complement the analysis with an access analysis. Accordingly, in this section we produce access scores with the EKD2SFCA method presented in equation (3) to obtain aggregate results for the 18 districts of continental Portugal. We consider only access to the existing publicly financed private providers, in which patients pay at maximum relatively low user fees. By restricting analysis to these providers, we can identify access inequalities due to an uneven distribution of the publicly financed supply capacity to satisfy demand.

As in the case of the competition assessment, we also use floating catchment areas of 30 minutes travel time for the computation of the access scores, and the initial catchment of 10 minutes for the application of the quartic distance decay function.

For the health needs index in equation (3) we used five variables, namely death by malignant tumors per population, the inverse of purchasing power per capita, percentage of illiterate population, percentage of population over 65 years old, and number of inpatients treated in public hospitals per 1,000 inhabitants, with data from the 278 municipalities of continental Portugal. (Note 5) Thus, we produced 278 health needs scores, and to each postcode area we attributed the health needs score of its correspondent municipality.

The commuting index was constructed with the following variables: employed or student population that uses primarily car, bus, train or metropolitan in commuting as a proportion of the population, average travel time in commuting (minutes), population that works or studies in another municipality as a proportion of total population, and employed or student population with commuting of over 60 minutes as a proportion of total population.

The two indices are first component indices constructed with principal components analysis (PCA), as explained by Polzin et al. (2014, 2016), following the methodology described by Henry et al. (2003), Salmond et al. (2006) and Mooi \& Sarstedt (2011). The relevant sets of variables were chosen with an iterative approach, following the Kaiser criterion and observing the specific criteria for the Kaiser-Meyer-Olkin (KMO) statistic, the Bartlett's Test of Sphericity, the communalities, and the percentage of the total variance attributed to the first component. Table 3 summarizes the complete process.

Table 3. Constructing an index with the first component of PCA

\begin{tabular}{ll}
\hline Process phase & Requirements \\
\hline & - Selection of variables that represent the desired factor; \\
Selection of the initial set of & - Correlations among the variables $>0.3$, but $<0.9 ;$ \\
variables & -10 to 20 variables; \\
& - Sample size of at least ten times the number of variables. \\
\hline & - KMO statistic: $>0.5$ is acceptable and $>0.7$ is adequate; \\
Iterative approach to define & - Rejection of the Bartlett's Test of Sphericity; \\
the relevant subset of & - Communalities $>0.3 ;$ \\
variables & - One factor with an eigenvalue $>1$ (Kaiser criterion); \\
& - First component accounts for at least $50 \%$ of the total variance. \\
\hline
\end{tabular}

After calculating the scores we apply cluster analysis for the identification of three clusters with a k-means algorithm, as in Polzin et al. (2014), and define the low access populations as the ones in the regions with scores grouped in the lowest cluster, and also the ones that cannot access publicly financed supply points in 30 minutes or less. Table 4 summarizes the results for the postcode areas, while Figure 4 illustrates the aggregated results for the districts, according to predominance in terms of affected populations.

Table 4. Distribution of the access scores across the three access levels

\begin{tabular}{llll}
\hline Statistic & Cluster & & \\
& Low & Medium & High \\
\hline Number of postcode areas & 368 & 81 & 10 \\
Population covered (\%) & 72.9 & 24.4 & 2.7 \\
Mean score (physicians per 100,000 inhabitants) & 1.7 & 11.9 & 28.2 \\
\hline
\end{tabular}






Figure 4. Access results

As the figures shows, predominant high and medium access results can only be found in three districts: Braga, Coimbra and Porto.

\section{Conclusions and Future Work}

This paper presents a practical application of the EKD4SFCA method, considering different ways of contracting private supply to better manage publicly financed supply capacity, in order to satisfy the populations' demand. It demonstrates how this method can be useful to accomplish the requirements defined by the Portuguese law to regulate the promotion of new publicly financed supply of diagnostic exams.

The combined access and competition analysis is carried out in a simple way by comparing the results presented in Figures 3 and 4. In the districts of Beja, Castelo Branco, Évora, Guarda and Viana do Castelo free adhesion contracts directed to new providers would be best to promote competition and increase access of the low access, disadvantaged populations. In the other 13 districts, public bids should be promoted to explore competition and attain lower prices. However, in three of these 13 districts the supply capacity should suffice already to satisfy demand: Braga, Coimbra and Porto. Therefore, the priority districts for the promotion of public bids are the following 10 districts: Aveiro, Bragança, Faro, Leiria, Lisbon, Portalegre, Santarém, Setúbal, Vila Real and Viseu.

Future work can involve the application of more sensitivity tests with variations of the sizes of the initial catchment and of the floating catchment areas. It can also include applications of the EKD4SFCA method in a similar way as presented here to other diagnostic exams that are financed by the Portuguese state. Also, aggregation of the results to other regions besides the districts could be managed, depending on the regions of interest for the promotion of public bids.

Supplementary potentially interesting variations of the specific application of the method for the purpose at hand could include changes to the variables and the PCA method applied for the health needs and commuting indices. 


\section{Acknowledgments}

AUTHOR1 received financial support from the Operational Program for Science and Innovation 2010 and the European Social Fund, via the Portuguese Foundation for Science and Technology, and from the Portuguese Health Regulation Agency, where he is currently working. However, the ideas, particular concepts and results expressed in this article are solely of the authors and do not reflect the views of any institution. The authors thank the audience of the International Conference on Economic Modeling 2016 (EcoMod 2016), where this paper was presented and valuable feedback was gathered.

\section{References}

Andersen, R. (1995). Revisiting the behavioral model and access to medical care: does it matter? Journal of Health and Social Behavior, 36(1), 1-10. https://doi.org/10.2307/2137284

CC. (2013). Guidelines for market investigations. Retrieved from https://www.gov.uk/government/uploads/system/uploads/attachment_data/file/284390/cc3_revised.pdf

EC. (1997). Commission Notice on the definition of relevant market for the purposes of Community competition law. Official Journal of the European Communities, C 372(3), 5-13.

Field, A., Miles, J., \& Field, Z. (2012). Discovering Statistics Using R. London: Sage.

Graves, A. (2009). A Model for Assessment of Potential Geographical Accessibility: A Case for GIS. Online Journal of Rural Nursing \& Health Care, 9(1), 46-55.

Gulzar, L. (1999). Access to health care. Journal of Nursing Scholarship, 31(1), 13-19. https://doi.org/10.1111/j.1547-5069.1999.tb00414.x

Halbersma, R. S., Mikkers, M. C., Motchenkova, E., \& Seinen, I. (2011). Market structure and hospital-insurer bargaining in the Netherlands. The European Journal of Health Economics, 12(6), 589-603. https://doi.org/10.1007/s10198-010-0273-z

Hellmer, S., \& Wårell, L. (2009). On the evaluation of market power and market dominance-The Nordic electricity market. Energy Policy, 37(8), 3235-3241. https://doi.org/10.1016/j.enpol.2009.04.014

Henry, C., Sharma, M., Lapenu, C., \& Zeller, M (2003). Microfinance Poverty Assessment Tool-CGAP Technical Tool series. Retrieved from http://documents.worldbank.org/curated/en/2003/10/2857591/microfinance-poverty-assessment-tool

Higgs, G. (2004). A Literature Review of the Use of GIS-Based Measures of Access to Health Care Services. Health Services and Outcomes Research Methodology, 5(2), 119-139. https://doi.org/10.1007/s10742-005-4304-7

Hirschman, A. O. (1964). The Paternity of an Index. The American Economic Review, 54(5), 761.

Hyndman, R. J., \& Athanasopoulos, G. (2013). Forecasting: principles and practice. Australia: OTexts.

Knoche, F., \& Thöni, M. (2011). Sozial- und wettbewerbsrechtliche Konflikte bei der Fusionskontrolle in der Gesetzlichen Krankenversicherung in Deutschland. Zeitschrift für die gesamte Versicherungswissenschaft, $100(4), 539-560$.

Luo, W., \& Wang, F. (2003). Measures of spatial accessibility to health care in a GIS environment: synthesis and a case study in the Chicago region. Environment and Planning B: Planning and Design, 30(6), 865-884. https://doi.org/10.1068/b29120

McGrail, M., \& Humphreys, J. S. (2009). A new index of access to primary care services in rural areas. Australian and New Zealand Journal of Public Health, 33(5), 418-423. https://doi.org/10.1111/j.1753-6405.2009.00422.x

McGrail, M., \& Humphreys, J. S. (2009). Measuring spatial accessibility to primary care in rural areas: Improving the effectiveness of the two-step floating catchment area method. Applied Geography, 29(4), 533-541. https://doi.org/10.1016/j.apgeog.2008.12.003

McGrail, M., \& Humphreys, J. S. (2009). The index of rural access: an innovative integrated approach for measuring primary care access. BMC Health Services Research, 9(1), 124. https://doi.org/10.1186/1472-6963-9-124

McIntosh, C., \& Hellmer, S. (2012). Necessary and sufficient conditions in merger control: the use of HHI and threshold value. Applied Economics, 44(7), 867-878. https://doi.org/10.1080/00036846.2010.524632 
Melnik, A., Shy, O., \& Stenbacka, R. (2008). Assessing market dominance. Journal of Economic Behavior \& Organization, 68(1), 63-72. https://doi.org/10.1016/j.jebo.2008.03.010

Mooi, E. A., \& Sarstedt, M. (2011). A Concise Guide to Market Research. The Process, Data and Methods using IBM SPSS Statistics. Berlin: Springer.

Polzin, P., Borges, J., \& Coelho, A. (2014). An extended kernel density two-step floating catchment area method to analyze access to health care. Environment and Planing B: Planing and Design, 41(4), 717-735. https://doi.org/10.1068/b120050p

Polzin, P., Borges, J., \& Coelho, A. (2016). A decision support method to identify target geographic markets for health care providers. Papers in Regional Science, 95(4), 843-863. https://doi.org/10.1111/pirs.12167

Rhoades, S. A. (1993). The Herfindahl-Hirschman Index. Federal Reserve Bulletin, 79(3), 188-189.

Salmond, C., Crampton, P., King, P., \& Waldegrave, C. (2006). NZiDep: A New Zealand index of socioeconomic deprivation for individuals. Social Science \& Medicine, 62(6), 1474-1485. https://doi.org/10.1016/j.socscimed.2005.08.008

Schuurman, N., Bérubé, M., \& Crooks, V. A. (2010). Measuring potential spatial access to primary health care physicians using a modified gravity model. Canadian Geographer / Le Géographe Canadien, 54(1), 29-45. https://doi.org/10.1111/j.1541-0064.2009.00301.x

Yang, D. H., Goerge, R., \& Mullner, R. (2006). Comparing GIS-Based Methods of Measuring Spatial Accessibility to Health Services. Journal of Medical Systems, 30(1), 23-32. https://doi.org/10.1007/s10916-006-7400-5

\section{Notes}

Note 1. We used data from OECD Stats and identified ARIMA models with the aid of the auto.arima function using R software (as a reference, see Hyndman \& Athanasopoulos (2013). Because of missing data, we used a time series from 1960 to 2003 to identify the model for the number of deaths, and then applied it to data from 2007 to 2013 (the identified model after transforming the series with a Box-Cox transformation was an ARIMA $(2,1,1)$ with drift). Population was forecasted using data from 1960 to 2013 (ARIMA $(2,1,2)$, after an inverse square root transformation).

Note 2. Data from 14th March 2016 of the Portuguese Health Regulation Agency's registry of health care providers, where we also collected data for the calculation of the markets shares and the identification of the competing firms, namely the owners of the supply points.

Note 3. Population data were collected from the Portuguese National Institute of Statistics.

Note 4. We applied the R functions friedman.test and friedmanme with default settings, as explained by Field et al. (2012).

Note 5. All data were collected from the Portuguese National Institute of Statistics, except the data for the number of inpatients, which are registered by the Portuguese Central Administration of the Health System.

\section{Copyrights}

Copyright for this article is retained by the author(s), with first publication rights granted to the journal.

This is an open-access article distributed under the terms and conditions of the Creative Commons Attribution license (http://creativecommons.org/licenses/by/4.0/). 